\title{
Methodology Adapted to the Practice of Judo for Older Men
}

\section{Claudio Joaquim Borba-Pinheiro ${ }^{* a, b, c, e ~(D), ~ A m a u r i ~ G o u v e i a-J r ~ a ~}$ D, Italo Sérgio Lopes Campos a (D), Edna Cristina Santos Franco a (D), Alam dos Reis Saraiva a,c (D), Délson Lustosa de Figueirêdo ${ }^{d, e}$ iD, Alexandre Janotta Drigo ${ }^{f}$}

a Center for Studies and Research in Combat Sports (NEPLEC) of the Federal University of Pará (UFPA) Belém, Pará state, Brazil

b Pará State University (UEPA) Tucuruí, Pará state, Brazil

c Federal Institute of Pará (IFPA), Tucuruí, Pará state, Brazil

${ }^{\mathrm{d}}$ State Department of Education, Sergipe state, Brazil

e Laboratório de Biociências da Motricidade Humana - LABIMH, Sergipe state, Brazil

f State University of São Paulo (UNESP) Julio de Mesquita Filho. Rio Claro, São Paulo state, Brazil

*Corresponding author Ph +55 9481700066; Email: claudioborba18@gmail.com

DOI: https://doi.org/10.34256/ijpefs2046

Received: 11-11-2020, Revised: 01-12-2020; Accepted: 02-12-2020; Published: 05-12-2020

Abstract: Our study presents a methodological proposal for the practice of judo as a viable, alternative exercise method to improve the health of older men and seniors. Bibliographic survey was utilized to analyze the results. A number of studies attempt to adapt the practice of judo to enhance different health variables in middle-aged and elderly men. The proposal of adapting judo methodology to older men was conceived based on these studies. The methodological proposal presented in this study corroborates the health and quality of life needs of judo enthusiasts, in addition to providing an opportunity for exercise that is normally appealing to men. In this respect, the methodological adaptations described in the present study may be an effective and viable way to prevent disease, maintain and promote health and quality of life, applying an exercise method that uses adapted judo training.

Keywords: Adapted exercise, Aging, Health promotion, Martial arts, Combat sports.

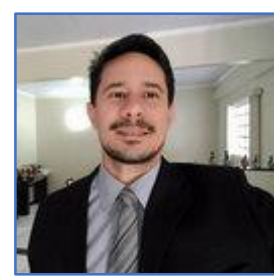

Dr. CLAUDIO JOAQUIM BORBA-PINHEIRO Graduated in Licenciature / Bachelor in Physical Education from the State University of Pará (UEPA-PA, 1996), Specialization in Judo (EsEFEx / UFRJ, 2001), Master in Human Motricity Sciences from the Castelo Branco University (UCB-RJ, 2009) and PhD in Science from the Federal University of the State of Rio de Janeiro (UNIRIO-RJ, 2013). He is currently a professor at the Federal Institute of Pará (IFPA) and the State University of Pará (UEPA) both on the campuses of Tucuruí-PA, Brazil. Center for Studies and Research on Fighting and Combat Sports (NEPLEC / UFPA).

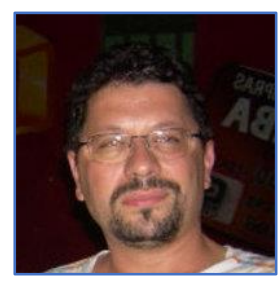

Dr. AMAURI GOUVEIA Jr Graduated in Psychology Degree from Universidade Estadual Paulista Júlio de Mesquita Filho (1993), Graduated in Psychologist Training from Universidade Estadual Paulista Júlio de Mesquita Filho (1993),
Master in Psychology (Experimental Psychology) from University of São Paulo (1996) and PhD in Neuroscience and Behavior from the University of São Paulo (2001). He is currently a member of the board of directors of the Research Support and Development Foundation of Pará, free from the National Institute of Educational Studies and Research Anísio Teixeira, ad hoc consultant to the National Council for Scientific and Technological Development and associate professor at the Federal University of Pará.

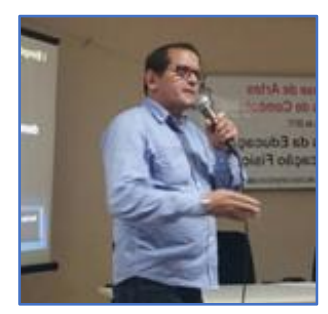

Dr. ÍTALO SÉRGIO LOPES CAMPOS has a degree in Physical Education from the State University of Pará (1985), a master's degree in Physical Education from the Gama Filho University (1999) and a doctorate in Neuroscience and Cell Biology from the Federal University of Pará (2017). $\mathrm{He}$ is currently an associate professor at the Federal University of Pará. In addition to being a professor, he is coordinator of the Physical Fitness Laboratory 
(LAFIS) and the Martial Arts Project at Ufpa. He has experience in the fields of cineanthropometry, sports training, physical exercise for special groups, aquatic physical training and physical preparation in combat sports, working in the following research groups, registered in the CNPq Directory: Modulatory Aspects of Behavior (UFPA) and in the Nucleus of Studies and Research in Fighting and Combat Sports - NEPLEC / UFPA, where he is Leader

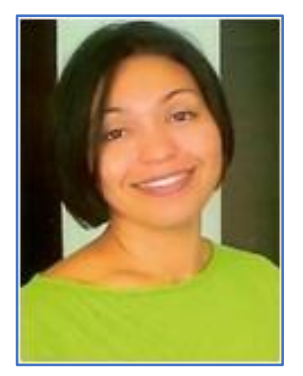

Dr. EDNA CRISTINA SANTOS FRANCO Graduated in Biological Sciences at UFPA (1998) and Degree in Physical Education at UNOPAR (2019). She has completed Bachelor of Physical Education at Unama. She holds a master's and doctorate in Neuroscience and Cell Biology from the Federal University of Pará. She has a specialization in Forensic Sciences from CESUPA (2013). She specializes in "Physical Exercise Applied to Special Groups: prevention and recovery from traumaorthopedic injuries" by VALORIZE and in "Sports Training" by UFPA. She is currently an associate researcher in the Pathology Section of the Evandro Chagas Institute. Has experience in teaching Higher Education in the disciplines Biochemistry, Cell Biology, Morphophysiological Sciences and Scientific Methodology. Master and PhD advisor at PPGNBC / UFPA.

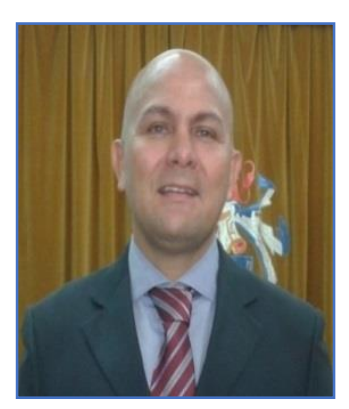

\section{Dr. ALAM DOS REIS} SARAIVA completed Bachelor and Licenciature Degree in Physical Education from the State University of Pará - UEPA (1995), Specialization in Sport and Leisure from UEPA (1999), Specialization in Judo from the Federal University of Rio de Janeiro (2000), Master in Science from Human Motricity at the Castelo Branco University (2009), PhD in Sport Sciences at the University of Tras-os Montes and Alto Douro - UTAD (2014) with VALIDATION at the University of São Paulo? USP and Post-Doctorate in Biodynamics of the Human Movement by UTAD, Portugal (2017). EBTT professor at the Federal Institute of Education, Science and Technology of Pará. He has experience in Physical Education and works mainly on the following topics: physical activity, quality of life, strength training, with an emphasis on Judo and fights

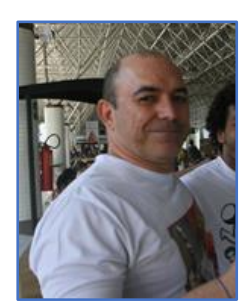

Dr. DELSON LUSTOSA DE FIGUEIREDO Graduated in Physical Education from the Federal University of Piauí (1992), graduated in Law from the Tiradentes University (2007), specialization in Sports Sciences from UNIFEC DO ABS São Caetano - SP
(1997), Master in Administration from the Federal University of Paraíba (2003), member of the Brazilian Association of Support and Development of Art Capoeira and currently pursuing a doctorate at the Federal University of the State of Rio de Janeiro UNIRIO. He is a capoeira professor at CAPOEIRA CONTEMPORANEA ASSOCIATION- PI (2018), effective professor of Physical Education at the State Department of Education in the State of Sergipe

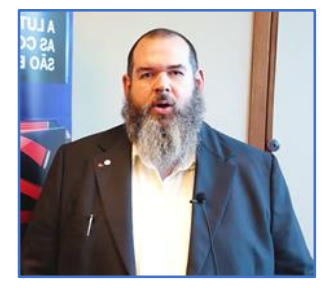

Dr. ALEXANDRE JANOTTA DRIGO Graduated in Bachelor of Biological Sciences at Universidade Estadual Paulista Júlio de Mesquita Filho (1994), Graduated in Bachelor of Physical Education at Universidade Estadual Paulista Júlio de Mesquita Filho (1998), Master in Motricity Sciences at Universidade Estadual Paulista Júlio de Mesquita Filho (2002) and PhD in Physical Education by the DCE of FEF / Unicamp (2007). He is currently accredited as Professor and advisor of the Graduate Program in Motor Sciences by UNESP, Campus Rio Claro. He has experience in the area of Physical Education and Biology, with an emphasis on Professional Training in Physical Education, working mainly with the following themes: Judo, Martial Arts, Professional Training. He is an Advisor to the Federal Council of Physical Education CONFEF, management 2016/2020.

\section{Introduction}

The transformation of judo into an Olympic sport required changes to the original proposal of its creator, Professor Jigoro Kano [1]. These involved modifying the scores and training methods used, making this combat sport more competitive and, consequently, less educational [2]. Although these changes are not exclusive to judo, their objectivity has helped establish the sport, with associated factors triggered by competition, including stress, anxiety, frustration and satisfaction [3].

These changes resulted in judo's becoming a sport practiced from childhood to advanced age [4]. Correia and Franchini [5], who conducted a review of the most important Brazilian martial arts and combat sports journals after the Federal Physical Education Council of Brazil (CONFEF) was established, found a predominance of studies on biodynamics (40\%), sociocultural foundations of human movement (32\%) and motor behavior (8\%). The studies were divided into the pedagogy of human movement $(10.7 \%)$, sport training $(8 \%)$, and sports management $(1.3 \%)$, but 
none on adapted human movement or, more specifically in the area of health.

The sports culture of judo and other combat sports, whose primary objective is athletic performance, caused a delay in the possible use of martial arts and combat sports as alternative healthbased exercise, in order to maintain physical performance variables, in addition to the cognitive, emotional and social aspects that decline with aging $[6,7]$. Exceptions are the studies on Tai Chi Chuan that focused on the health of elderly men and women [8,9]. Although, the results show benefits for body balance, functional autonomy and QoL, there are many controversies about the effects of Tai Chi for BMD $[8,9]$. Although some studies have used martial arts with methodological adaptations in search of health variable responses $[6,7,10]$, research on martial arts and combat sports remains largely ignored as alternative physical exercise for older adults, especially non-athletes.

Furthermore, there have been attempts to popularize the sport, but the target population remains children and young people [2]. This may also have been influenced by the origins of this physical activity, where discipline and exercise were aimed at schoolchildren in Japan [1].

It is important to underscore that the establishment of Judo in Brazil was independent of formal physical education [11]. The legal requirement to teach this modality is to be a black belt holder registered with the relevant federations and confederations. This often results in using the same artisanal training method learned from the judo master [12], which is essentially practical in terms of black belt training, while theoretical elements concentrate on judo specificities, especially a first aid course [12].

The aspects required for the black belt test reflect this, with little or no knowledge of training methodology or sport science necessary. The daily practice of judo on the mat prevails over theoretical, academic and scientific knowledge [12], which, although reported in the literature, remains far from the reality of judo academies.

This divergence between the academic study of judo and the artisanal training method does not serve the needs of older adults. The inclusion of this population in the sport of judo requires a revision of teaching methods [13-16] and teacher academic training to create new possibilities for different populations. These changes would increase the range of opportunities for judo teachers and those who engage in it $[12,17]$.

Judo training and the methodological aspects previously mentioned involve an approach aimed at high performance, prioritizing the amount and intensity of training $[18,19]$, as well as throws and takedowns, increasing the risk of injury [20] and emphasizing factors related to competition rather than training [3].

This focus on the competitive aspect of judo is unsuitable for non-combatants, meaning training methods must be adapted in order to become a health promoting technique that includes older people, given the increased longevity of this age group [13-16]. This modification may alter the current state of judo, in which the low number of active judoists aged 40 years or older are veterans of the modality [21].

Why introduce older adults and the elderly to judo? Because these individuals may potentially benefit from this modality and improve bone [21], and cardiorespiratory health $[6,7]$, and decrease the number of falls and injuries, in addition to being an environment where they can socialize and integrate [14-16, 22-24].

These gains offset some of the negative effects of aging, such as bone-articular problems, including arthritis, arthrosis, herniated disk, osteoporosis, cardiopulmonary and systemic blood pressure alterations, in addition to a decline in aspects involving functional autonomy, such as strength, flexibility and reaction speed [25].

Human aging is prevalent worldwide due to the decline in birth rates and increased longevity, showing the need for better strategic care of older adults and seniors in order to maintain their health, independence and QoL [26]. In this respect, different proposals have been put forth to maintain health, guarantee satisfaction, self-esteem and continuity of an active life in old age. To that end, although combat sports, specifically judo, promote comprehensive health in this age group, there is a need to create clearer guidelines for martial arts and combat sports methodology based on academic and scientific experiments in order to develop techniques that can safely reap the greatest benefits for this population [13-16].

We present a protocol aimed at promoting health rather than competition to enable men aged 40 years or older to engage in judo. It is believed that this proposal reconnects with the ideals of Jigoro Kano, the 
founder of the sport [1], allowing even greater dissemination of the modality, reintroducing former judo enthusiasts and introducing new devotees.

\section{Materials and Methods}

\subsection{Training proposal for judo adapted to men over $\mathbf{4 0}$ years of age}

The recommendations in this article here are based on methodological guidelines and adaptations for judo in older adults and seniors [13-16, 22] aimed at decreasing the risks inherent to the sport, such as falls, sprains, dislocations and ruptured tendons [16]. The proposed assessment and exercise prescription protocol is presented below.

\subsection{Adaptations for older adults and seniors}

Studies aimed at the effects of combat sports and martial arts on the health variables of older people have demonstrated numerous benefits that may favor maintaining an independent, active life with good QoL and continued contributions to society $[15,16,27]$.

According to DelCastillo-Andrés et al., [16], the search to improve the health and QoL of elderly European men has been a major social objective. Kokodan judo has been used for that purpose, where, as reported by Borba-Pinheiro et al., [13, 22, 23], traditional judo is adapted to a form denominated Adapted Utilitarian Judo (JUA) by DelCastillo-Andrés et al., [16], in order to better meet the needs of older adults using a utilitarian holistic mental and physical activity (judo for society). In this respect, JUA encompasses everything from the prevention and control of falls to the development of physical skills and qualities, not forgetting the social aspects that are important to this population, in keeping with the original principles of judo [1]. Moreover, both BorbaPinheiro [13,22-24] and DelCastillo-Andrés et al., [16] consider that adapted judo can open up new possibilities for transgenerational exercise (grandparents, parents, children and grandchildren), which is highly valued by older adults.

Mastnak [7] proposed a rapid intervention called Cardio-Judo, which is beneficial in cardiac rehabilitation, may increase the appeal of exercisebased rehabilitation, and help improve adherence. His study demonstrated that Cardio-Judo may provide a balance between strength training to enhance motor coordination and metabolic parameters, in addition to having positive effects on the psyche and behavior.
A number of case reports on combat sports show that methodology can be adapted to include elderly men in these modalities and exert positive effects on health-related variables that decline with age $[14,22]$. One of these studies reports that using karate with an adapted methodology for three months improved the functional autonomy, lower limb strength and QoL of a 75-year-old man with osteoporosis [22]. In another case study, a 76-year-old man also obtained improvements in health variables after judo training using adapted methodology, including localized upper and lower limb strength, and balance, in addition to greater bone mineral density (BMD) of the lumbar and trochanter [14].

Although these studies only describe a single case, they indicate new possibilities for experiments with groups of older men, focusing on health variables and a suitable methodological modification. According to the literature [13-16, 24], older men and seniors may benefit from the judo exercises and techniques contained in the methodological adaptation proposal presented in Table 1, provided they adhere to these changes.

\subsection{Judo for Bone Mineral Density (BMD)}

A study on judo adapted to premenopausal women with low bone mineral density (BMD) improved balance, lumbar BMD and QoL when compared to water aerobics and control groups. The adaptation consisted of twice-weekly 45 to 60 -minute classes using the following sequence: traditional judo salutations; warm-up divided into 1 - a series of 10 second stretching movements of large muscle groups and 2 - exercises for overall coordination, agility, strength, and balance, seeking the horizontal body position whenever possible, in order to decrease the force of gravity on the spine using movements that strengthen the abdominal and paravertebral region. The main exercises consisted of breaking falls (ukemis) with a forward, backward and lateral shoulder roll; the pinning techniques used were keza gatame and yoko shiro gatame; the throwing techniques were ashi barai, osoto-gari, koshi guruma and kibisu gaeshi, performed primarily using breakdowns. Also trained were fighting using preferred grip as well as attacking and defending. Throwing and freestyle training (randori) activities were not executed by women with low BMD, and when performed, were only done with experienced judoists. At the end of the class the same stretching exercises as those used in the warm-up were repeated, followed by the traditional salutations $[13,23,24]$. 
Table 1 - Summary of judo changes for older adults and seniors

\begin{tabular}{|c|c|c|}
\hline Practical Elements & Adapted Judo & $\begin{array}{l}\text { Differences from Olympic } \\
\text { judo }\end{array}$ \\
\hline 1. Periodic Exams & $\begin{array}{l}\text { Cardiac, bone, white and red series, lipids, } \\
\text { glycoses, screening for labyrinthitis }\end{array}$ & More age-related exams \\
\hline 2. Periodic assessments & $\begin{array}{l}\text { Body composition, functional autonomy, muscle } \\
\text { strength, hand grip strength, balance, anxiety, } \\
\text { depression and QoL. }\end{array}$ & $\begin{array}{l}\text { Emphasis on body } \\
\text { composition, lactate } \\
\text { tolerance, strength and } \\
\text { power }\end{array}$ \\
\hline 3. Environment & 40 mm-thick mat with a $30-\mathrm{cm}$ anti-slip platform & No special precautions \\
\hline 4. Physical conditioning & $\begin{array}{l}\text { Focuses on heart rate, blood pressure and the } \\
\text { spine; strengthening of muscle groups, functional } \\
\text { resistance training; } \\
\text { more stretching; controlled fall training }\end{array}$ & $\begin{array}{l}\text { More emphasis on aerobic } \\
\text { and strength training }\end{array}$ \\
\hline 5. Ukemis & $\begin{array}{l}\text { Break fall training with emphasis on protecting the } \\
\text { body }\end{array}$ & $\begin{array}{l}\text { Break fall training with } \\
\text { emphasis on protecting the } \\
\text { body }\end{array}$ \\
\hline 6. Utchi Komi & $\begin{array}{l}\text { Emphasis on correcting movement and not on } \\
\text { speed; Less emphasis on completing movements } \\
\text { with a fall; } \\
\text { fewer locks and chokes; change in attack angle of } \\
\text { hip techniques; use of renraku renka waza } \\
\text { (combination techniques) }\end{array}$ & Emphasis on completion \\
\hline 7. Shiai/Randori & $\begin{array}{l}\text { Under strict supervision, with attention to weight } \\
\text { distribution between competitors and skills; no } \\
\text { choking allowed }\end{array}$ & More similar to competition \\
\hline 8. Combat Time & $3 \mathrm{~min}$ & $5 \mathrm{~min}$ \\
\hline 9. Score & Maintain koka and yuko & Excluded \\
\hline 10. Objective & Health promotion & Competition \\
\hline
\end{tabular}

Legend: QoL = Quality of Life.

A more recent study demonstrated that postmenopausal women who engaged in adapted judo for 13 months obtained better spinal and femoral BMD when compared to the adapted karate and control group [22].

The data presented here $[13-16,22,23]$ reveal a trend that shows the viable and beneficial possibilities of judo with an adapted methodology for multiple health variables, QoL and the social aspects that decline with aging. The findings of these studies agree with official health entity recommendations for physical exercise such as protection, health promotion and maintenance and QoL in aging $[25,26,27]$.

Studies show that the regular practice of martial arts and combat sports produce beneficial effects for BMD in adolescents of both sexes [28], this shows that this type of exercise can be adapted for older adults and elderly of both sexes. A systematic review demonstrated that judo can enhance bone mass and metabolism in individuals of all ages and both sexes [29]. Furthermore, the study recommends that break fall techniques should be used in other sports and training regimes to protect against sprains and fractures, especially in the older and senior population with osteoporosis [29]. Study that also assessment QoL indicated that groups who engaged in adapted judo showed less fear of falling and avoidance of daily activities that could lead to falls when compared to resistance training, water aerobics and control groups. This fact may be due to the break fall techniques (ukemis) used [23]. Another systematic review study (30) shows that combat sports for the elderly, can also be an alternative for improving BMD and other variables of falls risk.

As such, we sought to create an adapted judo proposal capable of providing health benefits and controlling the risks for older men, as follows: 

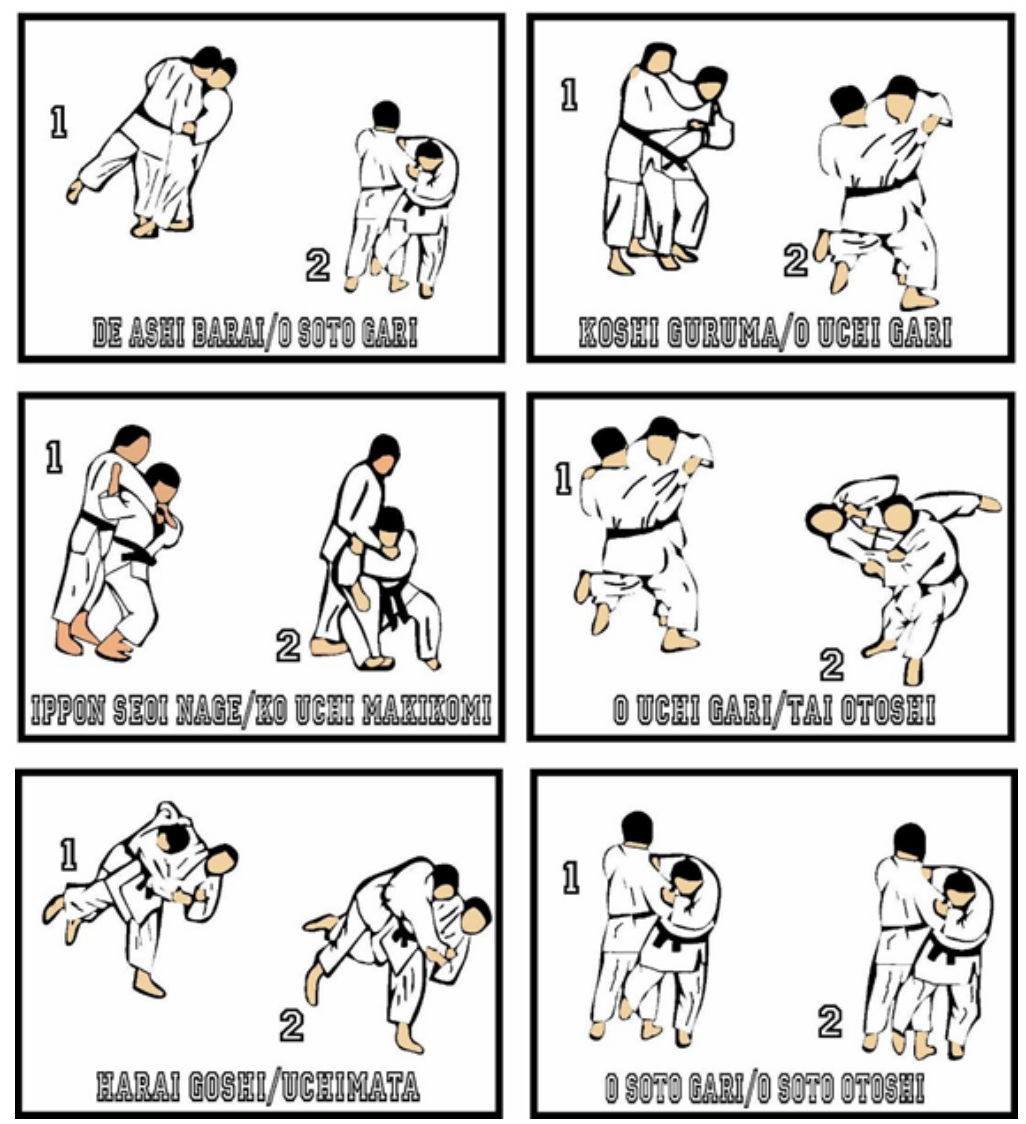

Figure 1 Presents a combination of basic techniques (Renraku Renka Waza) as a training suggestion

1) Pre-training and periodic exams:

Periodic routine exams should be performed as well as bone density and cardiovascular tests [25], due to the risk of injury and special care required for this population.

2) Training environment adaptations:

Ventilation and air conditioning should be adequate. The mat should be located on an antislip floor and steps should be clearly visible.

3) Pre-training physical conditioning:

Stretching and warm-up are indispensable. A period of muscle strengthening is recommended before specific training.

4) Assessment of localized muscle resistance and isometric force:

To determine localized exercises to decrease the risk of ligament rupture.

5) Assessment of dynamic balance:

Aimed at specific training and avoiding nausea or vertigo.

6) Uchikomi (repetition training) changes:

- Uchikomi can be identified for improved learning and execution, decreasing falling speed.

- Use Renraku Renka Waza, which is a combination of techniques, as shown in Figure 1. Attacks seek to force opponents off balance or throw them, the latter with low impact.

7) Changes in randori and score:

It is suggested that the original score be used, with koka and randori values and reduced time.

8) Greater emphasis on easy-to-execute throw techniques and takedowns below the waistline:

Avoid hip throws that strain the neck muscles and may cause spine and/or hip injuries.

9) Break fall Techniques Against Sprains and Fractures

Ukemis (break fall techniques) are part of basic judo training and can favor better control of dynamic and recovered balance, protecting the limbs, spine and head, thereby avoiding sprains and fractures caused by falling.

10) Figure 2 shows the four-main judo break fall techniques (ukemis): A - forward shoulder roll (mae mauare ukemi); B - sideways breakfall (yoko ukemi); C - forward breakfall (mae ukemi) and $\mathrm{D}$ - backward breakfall (ushiro ukemi).

11) Greater emphasis on katame-waza (grappling techniques):

The idea is that ground fighting decreases the chance of violent impacts from falling and allows 
greater energy expenditure in less time, and randori (fight training) can sometimes be initiated this way.

12) Change of focus from competition to health Teachers should focus on promoting health, not on training competitive Judoists.

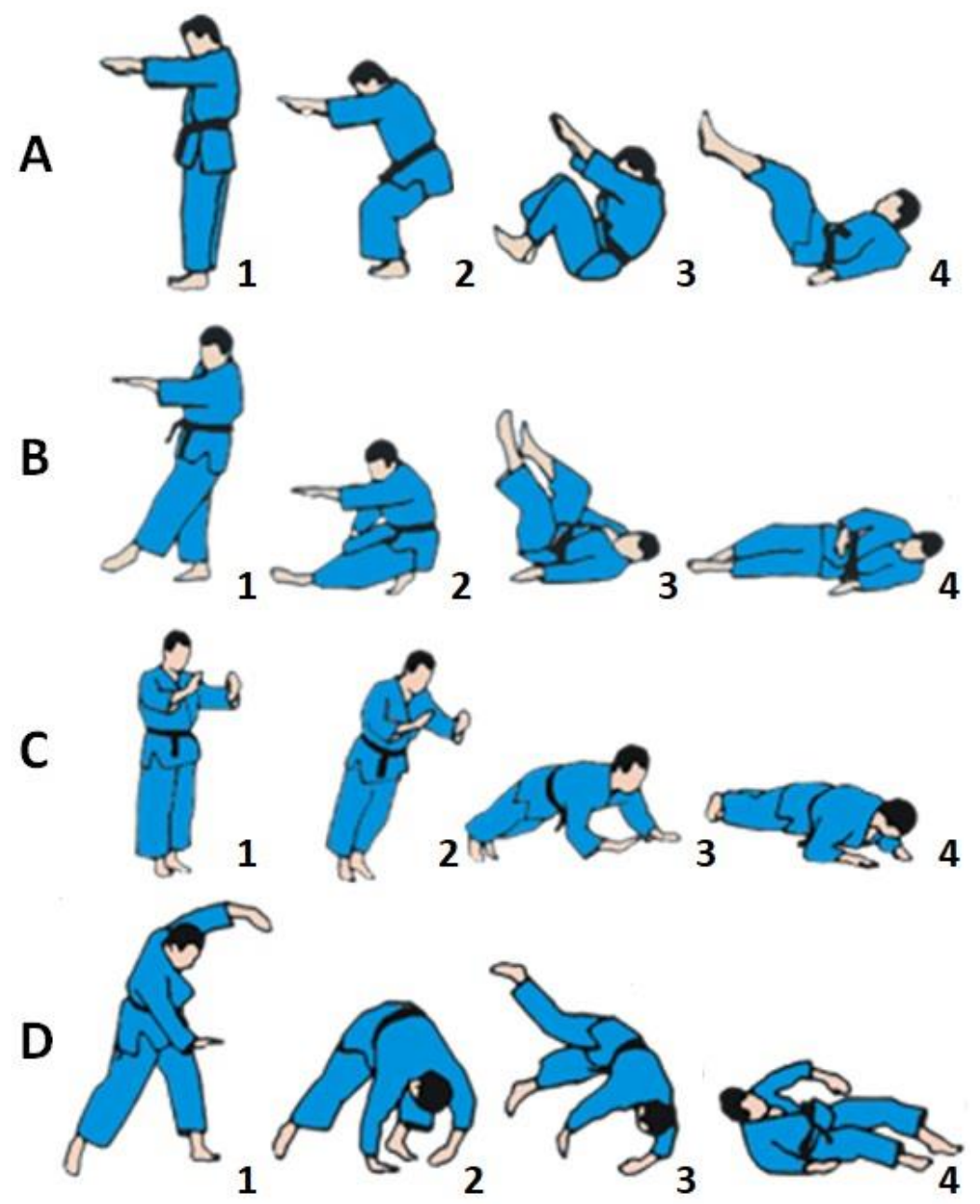

Figure 2 Shows fall control techniques (ukemis and zempo kaiten) as an important part of training

\section{Conclusion and Final Considerations}

Increased longevity has prompted older adults and seniors to enroll in exercise and health promotion programs. In the case of men, adapted judo may be more motivating since they are less involved in other types of activity for a number of reasons including embarrassment, considering them unnecessary, and sometimes because they refuse to take part in activities with significant female participation. As such, the methodological proposal presented here may be an effective and viable alternative to prevent disease, in addition to promoting and maintaining health, corroborating literature studies regarding the benefits of judo. It is important to highlight that most methodological studies of judo are aimed at children, adolescents and athletes. In this respect, our proposal may lead to further investigations with other populations, with a focus on health. Thus, systematic studies are suggested to formulate protocols for elderly men and train teachers on the adaptations required.

\section{References}

[1] Sakujiro Yokoyama, Eisuke Oshima, Yamakichi Horiguchi (Translator), (1915), JUDO, Nishodo Publisher, Tokyo.

[2] S.S. Arena, M.T.S. Böhme, Sports federation and competition organization for youths, Revista Brasileira de Ciência e Movimento. 12(4) (2004) 45-50. 
[3] I.S.L. Campos, A.R. Saraiva, Y.S. Campos, Y.S. Campos, J.R.A. Gouveia, Ganhar e perder em esportes de combate: descrição de elementos determinantes, Revista Brasileira de Ciência e Movimento, 24(4) (2016) 156-167.

[4] A.A.G. Simão, F.J. Aidar, C.F. Guimarães, D.G. Matos, A.R. Pereira, H.A. Junior, N.D.A. Barros, A.L. Carneiro, A.D.A. Bastos, Avaliação do lactato sanguíneo no Judo: Relação entre teste específico e situação de combate, Motricidade, 11(1) (2015) 153-160.

[5] W.R. Correia, E. Franchini, Produção acadêmica em lutas, artes marciais e esportes de combate, MOTRIZ - Revista de Educação Física, 16(1) (2010) 01-09. DOI

[6] W. Sikorski, W. Błach, Judo for health, Journal of Combat Sports and Martial Arts, 2(2) (2010) 123124.

[7] W. Mastnak, Cardio-Judo in Long-term Cardiac Rehabilitation. A Feasibility Study for Clinical Practice and Heart Support Groups, Journal of Combat Sports and Martial Arts, 8(1) (2017) 3742. DOI

[8] Liu FM, Wang S. Effect of Tai Chi on bone mineral density in postmenopausal women: A systematic review and meta-analysis of randomized control trials. J Chin Med Assoc. 80(12) (2017) 790-795. DOI

[9] L. Zou, C. Wang, K. Chen, Y. Shu, X. Chen, L. Luo, X. Zhao, The Effect of Taichi Practice on Attenuating Bone Mineral Density Loss: A Systematic Review and Meta-Analysis of Randomized Controlled Trials, International Journal of Environmental Research and Public Health, 14(9) (2017) 1000. DOI I PubMed

[10] C.J. Borba Pinheiro, E.H. Martin Dantas, O.R.M.D. Rocha Júnior, A.W. Monteiro, M.C.G.D. Alencar Carvalho, A. Janotta Drigo, N.M. Almeida Figueiredo, Fuerza muscular e independencia funcional de mujeres mayores después de un programa de entrenamiento de Kárate adaptado, Revista Ciencias de la Actividad Física, 16(1) (2015) 9-17.

[11] J.M.C. Barros, Educação Física: perspectivas e tendências na profissão, Motriz, 2(1) (1996) 4952.

[12] A.J. Drigo, Lutas e escolas de ofício: analisando o judô brasileiro, Motriz-revista de Educação Física, Univ Estadual Paulista-Unesp, Inst Biociencias, Rio Claro, 15(2) (2009) 396-406.

[13] C.J. Borba-Pinheiro, N.M.A. Figueiredo, M.C.G. Alencar, A. Janotta, E.H.M. Dantas, Can the Judo Training Improve the Muscle-skeletal Acting in
Older Women with Low Bone Mineral Density?, Journal of Human Sport and Exercise, 8(4) (2013) 1067-73.

[14] C.J. Borba-Pinheiro, N.M.A. Figueiredo, M.C.G.A. Carvalho, A.J. Drigo, P.J. Pardo, E.H.M. Dantas, Efecto del entrenamiento de judo adaptado en la osteoporosis masculina: presentación de un caso, Rev Ciencias de la Actividad Física UCM, 14(2) (2013) 15-19.

[15] C.J. Borba-Pinheiro, M.C.G.A. Carvalho, A.J. Drigo, N.S.L. Silva, C.S. Pernambuco, N.A. Figueiredo, E.H.M. Dantas, Combining adapted Judo training and pharmacological treatment to improve Bone Mineral Density on postmenopausal women: a two years study. Archives of Budo, 9(2) (2013) 81-88. DOI

[16] O. DelCastillo-Andrés, M.C. Campos-Mesa, G. González-Campos, C. Castañeda, F.ChacónBorrego, J.A. Corral et al. Adapted utilitarian judo (JUA): program to improve health and quality of life for older adults: judo black belt of experience. In: H. Sertic, S. Corak, I. Segedi, Applicable judo in research. 3rd European Science of Judo Research Symposium 2nd Scientific and Professional Conference on Judo, 2016.

[17] A.J. Drigo, J. Cesana, L.H. Silva, Atuação do profissional de Educação Física na área da saúde: aplicações na osteoporose. In: C. J. Borba-Pinheiro, N. M. Figueiredo, E.H. M. Dantas, Ações multiprofissionais sobre o idoso com osteoporose: um enfoque no exercício físico, SP: Yendis, 2016.

[18] P.H.S.M. Azevedo, A.J. Drigo, M.C.G.A. Carvalho, J.C. Oliveira, J.E.D. Nunes, V. Baldissera, S.E.A. Perez, Determination of Judo Endurance Performance Using the Uchi - Komi Technique and an Adapted Lactate Minimum Test, Journal of Sports Science Medicine, 6(CSSI-2) (2007) 10-14. PubMed

[19] A.R. Saraiva, C.J. Borba-Pinheiro, V.M. Reis, J.L. Bitencourt da Silva, A.J. Drigo, L.J. MatarunaDos-Santos, J. S. Novaes, Order of Strength Exercises on the Performance of Judo Athletes, Revista Internacional de Medicina y Ciencias de la Actividad Fisica y del Deporte, 17(68) (2017) 605-617. DOI

[20] M.M. Gonçalves, C.J. Borba-Pinheiro, R.A. Marson, L.R. Camposo, A.R. Saraiva, J.S. Novaes, Correlation between maximum isometric strength variables and specific performance of Brazilian military judokas, Motricidade, 13(1) (2017) 68-76. 
[21] J.K. Lazzoli, M.A.B. Oliveira, M.B. Leitão, A.C.L. Nóbrega, R.M.N. Nahas, L. Rezende, Posicionamento Oficial da Sociedade Brasileira de Medicina do Esporte sobre Esporte Competitivo em Indivíduos acima de 35 anos, Revista Brasileira de Medicina do Esporte, 7(3) (2001) 83-92. DOI

[22] C.J. Borba-Pinheiro, E.H.M. Dantas, F.P. Jesus, Rocha-Junior, A.J. Drigo, M.C.G. Carvalho, N.M.A. Figueiredo, Adapted karate training on functional autonomy, muscle strength and quality of life of elderly man with osteoporosis: a clinical case, Archives Budo Science Martial Arts \& Extreme Sports, 12 (2016) 71-76.

[23] C.J. Borba-Pinheiro, M.C.G. de Alencar Carvalho, N.S.L. da Silva, A.J. Drigo, J.C. Pereira Bezerra and E.H. Martin Dantas, Bone Density, Balance and Quality of Life of Postmenopausal Women Taking Alendronate, Participating in Different Physical Activity Programs, Therapeutic Advances in Musculoskeletal Disease, 2(4) (2010) 175-85. DOI | PubMed

[24] C.J. Borba-Pinheiro, E.H.M. Dantas, R.G.S. Vale, A.J. Drigo, M.C.G.A. Carvalho, T. Tonini, E.I.A. Meza, N.M.A. de Figueiredo, Adapted combat sports on bone related variables and functional independence of postmenopausal women in pharmacological treatment: a clinical trial study, Archives of Budo, 12 (2016) 187-199.

[25] American College of Sports Medicine (ACSM), Diretrizes para testes de esforço e sua prescrição. 9 ed. Rio de Janeiro: Guanabara, 2014.

[26] Organização Mundial Da Saúde (OMS), Resumo: Relatório Mundial de Envelhecimento e Saúde. WHO/FWC/ALC/15.01. 2015.

[27] B. Sparling Phillip, J. Howard Bethany, W. Dunstan David, Owen Neville, Recommendations for physical activity in older adults, BMJ, 350 (2015) h100. DOI | PubMed

[28] I.H. Ito, A.M. Mantovani, R.R. Agostinete, P.C. Junior, E.F. Zanuto, D.G.D. Christofaro, L.P. Ribeiro, R.A. Fernandes, Practice of martial arts and bone mineral density in adolescents of both sexes, Rev Paulista de Pediatria (English Edition), 34(2) (2016) 210-215. DOI I PubMed

[29] S. Ciaccioni, G. Condello, F. Guidotti, L. Capranica, Effects of Judo Training on Bones: A Systematic Literature Review, The Journal Strength \& Conditioning Research, 33(10) (2019) 2882-2896. DOI | PubMed

[30] C.J.O. Barbeta, T. Krahenbühl, E.M.G. GuerraJúnior, Effects of combat sports on bone mass: systematic review, Revista Brasileira de Medicina do Esporte, 25(3) (2019) 240-244. DOI

\section{Acknowledgement}

Nil

\section{Funding \\ Nil.}

\section{Authors Contribution}

Individual contributions are as follows: Claudio Joaquim Borba-Pinheiro, Amauri Gouveia-Jr and Italo Sérgio Lopes Campos - Study Desing, Manuscript Preparation, Funds collection; Edna Cristina Santos Franco and Alam dos Reis Saraiva - Study Desing, Funds collection; Délson Lustosa de Figueirêdo - Study Desing, Manuscript Preparation; Alexandre Janotta Drigo - Study Desing, Manuscript Preparation, Funds collection. All authors have read and approved the manuscript.

\section{Ethics Approval \\ Not Applicable \\ Conflict of interest \\ Nil}

Availability of data and material

No additional data are available

Informed consent

Not Applicable

\section{About The License}

(c) The author(s) 2020. The text of this article is open access and licensed under a Creative Commons Attribution 4.0 International License 